\title{
Numerical Modeling of Basic Physical Phenomena During the Creation Process of Casting-Riser System
}

\author{
L. SowA* \\ Department of Mechanics and Machine Design Fundamentals, \\ Częstochowa University of Technology, 42-201 Częstochowa, Poland \\ Doi: 10.12693/APhysPolA.139.602 \\ *e-mail: $\quad$ sowa@imipkm.pcz.pl
}

\begin{abstract}
The work concerns the use of differential equations to modeling the process of manufacturing machine parts by a casting method. Making a casting with good strength properties is a difficult task and usually requires numerous computer simulations and their experimental verification at the prototyping stage. Computer simulations are then of priority importance in determining the appropriate parameters of the casting process and in selecting the dimensions of the riser for the casting fed with it. This requires complex mathematical and numerical models that take into account thermal, flow and contraction phenomena, but allow obtaining the results of numerical simulations effectively. The aim is to obtain a casting free from shrinkage defects. This type of research is still valid and requires continuous development. The paper presents the mathematical model and the results of numerical simulations of the casting creation process. The basic physical phenomena of the metal solidification process in the casting-riser system were modeled using the Finite Element Method (FEM). A partial differential equation describing the course of thermal phenomena in the process of $3 \mathrm{D}$ casting creation was applied. This equation was supplemented with appropriate boundary and initial conditions that define the physical problem under consideration. In numerical simulations, by selecting the appropriate riser, an attempt was made to obtain a casting without internal defects, using a simple method of identifying their location. This is the main aim of the research as such defects in the casting disqualify it from use.

topics: solidification, numerical simulations, heat transfer, FEM
\end{abstract}

\section{Introduction}

Constantly increasing customer demands for the production of high-quality castings result in an intensive technological development of their production methods demanding continuous researches. These studies are mainly aimed at obtaining castings without internal defects of the high strength properties $[1,2]$. Research on real objects is difficult due to high temperatures occurring there, which is why computer simulations make it possible to improve casting methods [1-10]. For the analysis of the casting process in a three-dimensional space, an appropriate mathematical model should be formulated, taking into account only the most important phenomena occurring in the casting creation process. It is connected with the necessity to obtain an effective numerical solution, especially when we only have a general-purpose program while performing numerical simulations $[5-7,10]$. The complexity of the mathematical model is less important in the case of expensive programs mainly dedicated to foundry $[1-4,9]$. Some researchers neglect the movements of liquid metal in the numerical analysis of the solidification process [5-7], but, in turn, they focus on the analysis of the formation and growth of a shrinkage cavity in the casting process [7].

This article analyzes the solidification process of a casting using a model in which the movements of the molten metal were neglected. By comparing the obtained calculation results with the results presented in [9], obtained taking into account the movements of the liquid metal, their good agreement can be stated. The effectiveness of feeding the casting through the molten metal from the riser was checked with the assumed dimensions of the riser in the shape of a cylinder or a cone. By observing the permanently changing shape of the solidus line, it was assessed whether it was closed in the area of the casting feed. Such a situation would mean no feeding of this area with liquid metal from the riser and the formation of shrinkage defects at this point of the casting. We avoid this situation by selecting the appropriate shape of the riser for the casting under consideration, which was the aim of this work. 


\section{Mathematical model}

The proposed model for the numerical simulation of a casting solidification is based on the solution of the heat conductivity equation [5-8]:

$$
\begin{aligned}
& \nabla \cdot(\lambda(T) \nabla T(\boldsymbol{r}, t))+\rho_{\mathrm{s}} L \frac{\mathrm{d}}{\mathrm{d} t} f_{\mathrm{s}}(T(\boldsymbol{r}, t))= \\
& \rho C(T) \frac{\partial T(\boldsymbol{r}, t)}{\partial t},
\end{aligned}
$$

where: $T$ - the temperature $[\mathrm{K}], \lambda(T)$ - the thermal conductivity coefficient $[\mathrm{W} /(\mathrm{m} \mathrm{K})], \rho(T)$ - the density $\left[\mathrm{kg} / \mathrm{m}^{3}\right], C(T)$ - the specific heat $[\mathrm{J} /(\mathrm{kg} \mathrm{K})], L$ - the latent heat of solidification $[\mathrm{J} / \mathrm{kg}], f_{s}$ - the volume fraction of solid phase $f_{\mathrm{s}} \in[0,1], \rho_{s}$ - the density of solid phase $\left[\mathrm{kg} / \mathrm{m}^{3}\right]$, $t$ - the time [s] and $\boldsymbol{r}(x, y, z)$ - the coordinates of the vector of a considered node's position [m].

Since the solidification front has been assumed as fuzzy, the internal heat sources are not evident in the equation of heat conductivity. Thus, the differential equation is assumed in the form [5-8]

$$
\nabla \cdot(\lambda \nabla T)-\rho C_{\mathrm{ef}} \frac{\partial T}{\partial t}=0 .
$$

In the applied model of solid phase growth, the heat of phase transformation to the effective specific heat is introduced. In addition, assuming the linear function of the solid phase fraction, the effective specific heat $\left(C_{\text {ef }}\right)$ for each phase is determined as follows [5-7]

$$
C_{\text {ef }}(T)= \begin{cases}c_{\mathrm{l}}(T), & T>T_{\mathrm{l}}, \\ c_{\mathrm{ls}}(T)+\frac{L}{T_{1}-T_{\mathrm{s}},}, & T_{\mathrm{s}}<T<T_{1}, \\ c_{\mathrm{s}}(T), & T<T_{\mathrm{s}},\end{cases}
$$

where $T_{1}, T_{\mathrm{s}}$ - the liquidus and solidus temperature of the analyzed alloy $[\mathrm{K}]$ and $c_{\mathrm{l}}, c_{\mathrm{ls}}, c_{\mathrm{s}}$ - the specific heat of the liquid phase, the mushy zone and the solid phase $[\mathrm{J} /(\mathrm{kgK})]$, respectively.

The heat conductivity equation (2) was supplemented with appropriate initial conditions and the boundary conditions.

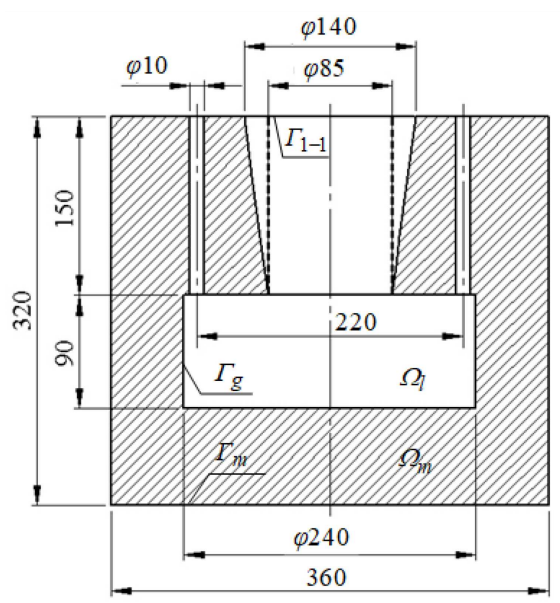

Fig. 1. The cross-section of the casting-mould system and identification of sub-regions of the considered region.
The initial conditions for temperature fields are given as [5-7]

$$
T\left(\boldsymbol{r}, t_{0}\right)=T_{0}(x, y, z)=\left\{\begin{array}{lll}
T_{\mathrm{m}} & \text { on } & \Gamma_{\mathrm{g}} \\
T_{i n} & \text { in } & \Omega_{\mathrm{l}} \\
T_{\mathrm{m}} & \text { in } & \Omega_{\mathrm{m}}
\end{array} .\right.
$$

The boundary conditions, on the indicated surfaces (Fig. 1), specified in the considered problem were as follows [5-7]:

$$
\begin{aligned}
& \left.\lambda_{\mathrm{m}} \frac{\partial T_{\mathrm{m}}}{\partial n}\right|_{\Gamma_{\mathrm{m}}}=-\alpha_{\mathrm{m}}\left(\left.T_{\mathrm{m}}\right|_{\Gamma_{\mathrm{m}}}-T_{\mathrm{a}}\right), \\
& \left.\lambda_{\mathrm{s}} \frac{\partial T_{\mathrm{s}}}{\partial n}\right|_{\Gamma_{\mathrm{g}-}}=\left.\lambda_{\mathrm{g}} \frac{\partial T_{\mathrm{g}}}{\partial n}\right|_{\Gamma_{\mathrm{g}-}}, \\
& \left.\lambda_{\mathrm{g}} \frac{\partial T_{\mathrm{g}}}{\partial n}\right|_{\Gamma_{\mathrm{g}+}}=\left.\lambda_{\mathrm{m}} \frac{\partial T_{\mathrm{m}}}{\partial n}\right|_{\Gamma_{\mathrm{g}+}},
\end{aligned}
$$

and also

$$
\left.\frac{\partial T}{\partial n}\right|_{\Gamma_{1-1}}=0
$$

where $T_{\mathrm{a}}$ is the ambient temperature $[\mathrm{K}], T_{\mathrm{m}}$ and $T_{\mathrm{g}}$ - the temperature of the mould and the gap (protective coating) $[\mathrm{K}]$, respectively, $\lambda_{\mathrm{m}}, \lambda_{\mathrm{g}}$ and $\lambda_{\mathrm{s}}$ the thermal conductivity coefficient of the mould, the gap and the solid phase, respectively $[\mathrm{W} /(\mathrm{m} \mathrm{K}]$, $\alpha_{\mathrm{m}}$ - the heat-transfer coefficient between the mould and ambient $\left[\mathrm{W} /\left(\mathrm{m}^{2} \mathrm{~K}\right)\right]$ and $n$ - the outward unit normal surface vector $[\mathrm{m}]$.

The numerical model uses the finite element method in the weighted residuals formulation [5-8].

\section{Examples of numerical calculations}

To analyze the impact of the riser shape on solidification of the casting, the following threedimensional system of casting-mould was considered (Fig. 1). The mould is a cross section $360 \times 320$ and $360 \mathrm{~mm}$ in thickness and its internal surface is covered with an insulating coat. This insulating coat is made from a water suspension of quartzite dust with $2 \mathrm{~mm}$ thickness. The overall dimensions of the casting are equal to $\varphi 240 \times 90 \mathrm{~mm}$. Since the computer calculations of the casting together with the conical or cylindrical riser are made, the dimensions of the cylindrical riser amount to $\varphi 85 \times 150 \mathrm{~mm}$ and of the conical riser are equal $\varphi 85 \times \varphi 140 \times 150 \mathrm{~mm}$.

The numerical calculations were carried out for the casting made of low-carbon cast steel and the steel mould. The thermo-physical properties were taken from $[1,2,5]$ and are summarized in Table I for the casting and Table II for other regions under consideration.

The overheated metal with temperature of $T_{i n}=1850 \mathrm{~K}$ was poured into the steel mould with initial temperature $T_{\mathrm{m}}=350 \mathrm{~K}$. The heat-transfer coefficient between the mould and ambient was equal to $\alpha_{\mathrm{m}}=200 \mathrm{~W} /\left(\mathrm{m}^{2} \mathrm{~K}\right)$ and on the upper surface of the riser between the slag and ambient $\alpha_{\mathrm{s}}=1 \mathrm{~W} /\left(\mathrm{m}^{2} \mathrm{~K}\right)[5,7]$. The ambient temperature $T_{\mathrm{a}}$ was equal to $300 \mathrm{~K}$. 
TABLE I

Material properties of the casting — cast steel.

\begin{tabular}{c|c|c}
\hline \hline Material property & Liquid phase & Solid phase \\
\hline$\rho\left[\mathrm{kg} / \mathrm{m}^{3}\right]$ & 7300 & 7800 \\
$C[\mathrm{~J} /(\mathrm{kg} \mathrm{K})]$ & 830 & 644 \\
$\lambda[\mathrm{W} /(\mathrm{m} \mathrm{K})]$ & 23 & 45 \\
\hline \multicolumn{2}{|c}{ Additional parameters } \\
\hline$T_{1}[\mathrm{~K}]$ & 1810 \\
$T_{\mathrm{s}}[\mathrm{K}]$ & 1760 \\
$L[\mathrm{~J} / \mathrm{kg}]$ & 270000
\end{tabular}

TABLE II

Material properties used in the calculations for other regions.

\begin{tabular}{c|c|c}
\hline \hline Material property & Mould & Protective coating \\
\hline$\rho\left[\mathrm{kg} / \mathrm{m}^{3}\right]$ & 7200 & 1600 \\
$C[\mathrm{~J} /(\mathrm{kg} \mathrm{K})]$ & 600 & 1670 \\
$\lambda[\mathrm{W} /(\mathrm{m} \mathrm{K})]$ & 42 & 0.3
\end{tabular}

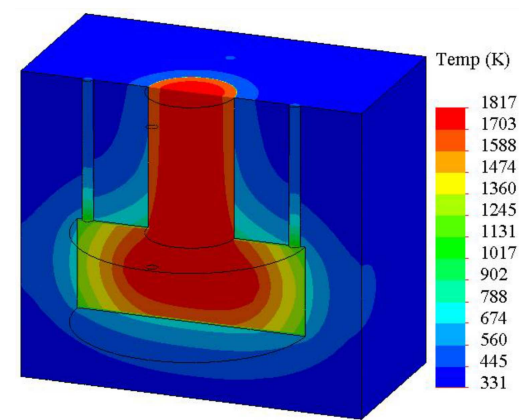

Fig. 2. Temperature distribution at $t=200 \mathrm{~s}$ (variant I).

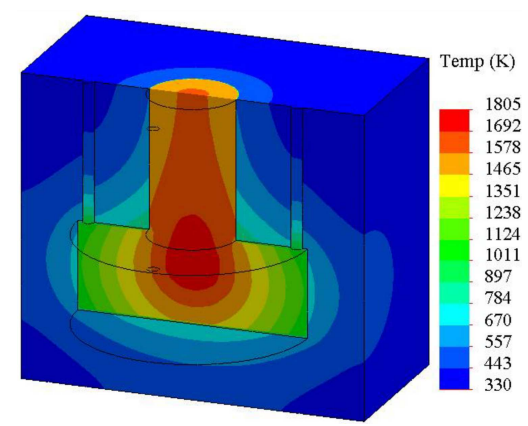

Fig. 3. Temperature distribution at $t=325 \mathrm{~s}$ (variant I).

The professional SolidWorks Simulation program was used for the calculations. Transient analysis of the heat flow was carried out only by conduction but with the change of the cooled metal phase, modeled by temperature-dependent material properties in the liquid phase of the solidifying region. The geometry of the system was divided into 545299 tetrahedral finite elements that are defined by 742553 mesh nodes.

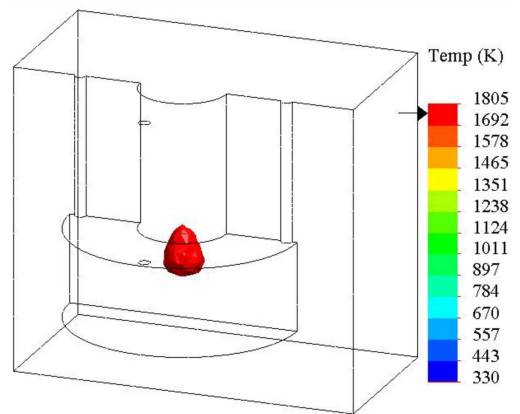

Fig. 4. Temperature field above the solidus temperature after $325 \mathrm{~s}$ (variant I).

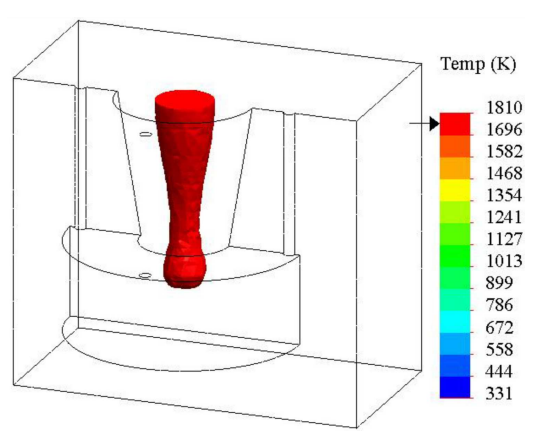

Fig. 5. Temperature field above the solidus temperature after $325 \mathrm{~s}$ (variant II).

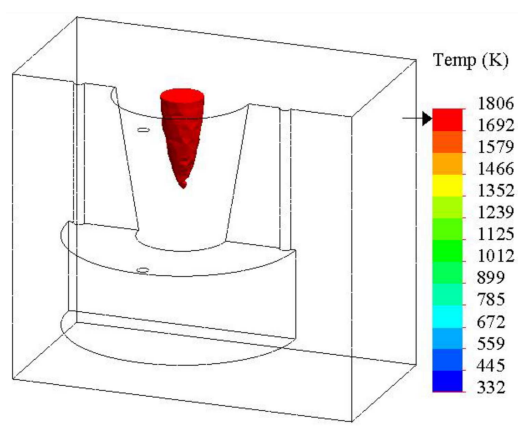

Fig. 6. Temperature field above the solidus temperature after $375 \mathrm{~s}$ (variant II).

The calculations were made for two riser shapes: cylindrical (variant I) or conical (variant II). The main difference between variants I and II consists in the shape of the riser. The possibility of reducing material consumption per riser was assessed, while maintaining its functionality for feeding the casting. Thermal phenomena, which proceeded in the mould cavity until total solidification of the casting, were analyzed (Figs. 2-6). The influence of the shape change of the riser on the temperature distribution in particular parts of the casting solidifying inside the steel mould was determined.

Examples of calculation results are shown in the form of temperature fields in Figs. 2-4 for the casting together with the cylindrical riser or in Figs. 5 and 6 for the conical riser. A continuous moving 
of the solidus line during the process of directional solidification of the molten metal was observed, because it gives information about forming the casting without shrinkage defects. If this line moves fluently to the riser, where the solidification process of the considered system should end, the casting free of defects will be created (Fig. 6), if not, the defect will form in the casting (Figs. 3 and 4).

\section{Conclusions}

The work concerns a computer simulation of the unsteady process of the cast steel solidification in a metal mould using the finite element method. The solidification process of the molten metal in the three-dimensional cast-riser-mould system was analyzed, evaluating whether the conditions are conducive to the formation of shrinkage defects. Numerical calculations were made with the assumption of a cylindrical or conical riser, obtaining temperature fields allowing to follow the position of the solidus line in subsequent calculation stages (Figs. 2-6). It was observed whether this line was not closing, disconnecting the solidifying casting into smaller areas with a difficult supply to them of liquid metal, because this would result in a formation of a shrinkage cavity in this place. In the final solidification period of the system casting-cylindrical riser, closing of the solidus line and location of the shrinkage cavity in the upper part of the casting was observed (Figs. 3 and 4), which proves that such a riser did not fulfill its task. Changing the shape of the riser to the conical one caused the end of solidification to occur in the upper part of the riser, which is allowed, because the riser with the shrinkage cavity created in this way is cut off and reprocessed (Fig. 6). Thus, the aim of this work was achieved, because the appropriate riser was selected for the solidifying casting in the metal mould so that it was created without shrinkage defects.

\section{References}

[1] J. Hajkowski, P. Roquet, M. Khamashta, E. Codina, Z. Ignaszak, Arch. Foundry Eng. 17, 57 (2017).

[2] P.H. Huang, C.J. Lin, Int. J. Adv. Manuf. Technol. 79, 997 (2015).

[3] S.L. Nimbulkar, R.S. Dalu, Perspect. Sci. 8, 39 (2016).

[4] P.H. Huang, J.K. Kuo, T.H. Fang, W. Wu, MATEC Web of Conf. 185, 00008 (2018).

[5] L. Sowa, T. Skrzypczak, P. Kwiatoń, MATEC Web of Conf. 254, 02016 (2019).

[6] A.S. Jabur, F.M. Kushnaw, J. Appl. Computat. Math. 6, (2017).

[7] T. Skrzypczak, E. Wegrzyn-Skrzypczak, L. Sowa, Acta Phys. Pol. A 138, 308 (2020).

[8] R.W. Lewis, E.W. Postek, Z. Han, D.T. Gethin, Int. J. Numer. Methods Heat Fluid Flow 16, 539 (2006).

[9] I. Malik, A.A. Sani, A. Medi, J. Phys.: Conf. Ser. 1500, (2020).

[10] P. Kwiatoń, D. Cekus, M. Miara, I. KubikMaciagg, Acta Phys. Pol. A 138, 276 (2020). 